\title{
Pilot tests of $\mathrm{CO}_{2}$ capture in brick production industry using gas-liquid contact membranes
}

\author{
D. Koutsonikolas ${ }^{1}$ - G. Pantoleontos ${ }^{1,2} \cdot$ M. Mavroudi $^{1} \cdot$ S. Kaldis $^{1}$ \\ A. Pagana ${ }^{1,2} \cdot$ E. S. Kikkinides ${ }^{2} \cdot$ D. Konstantinidis ${ }^{3}$
}

Received: 26 May 2015 / Accepted: 22 September 2015/Published online: 5 November 2015

(c) The Author(s) 2015. This article is published with open access at Springerlink.com

\begin{abstract}
It is generally accepted that carbon capture and storage strategies will play a crucial role for mitigating $\mathrm{CO}_{2}$ emissions at short- and mid-term scenarios. In this study, a membrane gas absorption process was assessed as potential candidate method for $\mathrm{CO}_{2}$ capture in a Greek brick production industry. The membrane contactor pilot unit was installed near the flue, where a slip stream of the flue gases was continuously sampled and fed in the hollow fiber membrane module. A $0.25 \mathrm{M}$ aqueous diethanolamine solution was used as a typical solvent for $\mathrm{CO}_{2}$ capture. The $\% \mathrm{CO}_{2}$ removal was chosen as a typical performance indicator and the liquid to gas flow ratio was chosen as the main controlling variable of the process. The test results indicate that almost complete $\mathrm{CO}_{2}$ removal can be attained with a liquid to gas flow rate around 1, demonstrating the high potential of the proposed technology.
\end{abstract}

Keywords $\mathrm{CO}_{2}$ capture $\cdot$ Membrane contactors · Membrane absorption · Gas-liquid contact membranes

D. Koutsonikolas

dkoutson@cperi.certh.gr

1 Chemical Process and Energy Resources Institute, Centre for Research and Technology Hellas, P.O. Box 1520, 54006 Thessaloníki, Greece

2 Department of Mechanical Engineering, University of Western Macedonia, Bakola \& Salvera Str., 50100 Kozani, Greece

3 ESTIA Consulting and Engineering S.A., 1st km ThermiAirport, P.O. Box 60649, 57001 Thessaloníki, Greece

\section{Introduction}

It has been generally stated that climate change through global warming is one of the most serious environmental threats that humankind is facing; therefore, greenhouse gas emissions (GHG's) should be reduced in every field of activities. During the last two decades, there was a growing scientific consensus that the rising atmospheric levels of $\mathrm{CO}_{2}$ as a result of man-made activities (e.g., fossil fuel burning, cement and lime production, ammonia and ethylene oxide synthesis, aluminum and glass industries, fermentation, deforestation, use of fertilizers, etc.) are responsible for around two-thirds of the greenhouse effects, while $\mathrm{CO}_{2}$ was recognized as the most significant anthropogenic greenhouse gas. For this reason, there is a pressing need to find ways for reducing $\mathrm{CO}_{2}$ levels in the atmosphere. The three possible ways towards this direction are: (1) increase of energy efficiency, (2) change of the fossil fuels to non-carbon forms of energy (e.g., renewable and nuclear energy) and (3) create $\mathrm{CO}_{2}$ sinks with the help of carbon capture and storage (CCS) technologies. Among these CCS is visualized as a promising strategy for mitigating $\mathrm{CO}_{2}$ emissions at short- and mid-term scenarios. In many industry sectors, CCS is the only technology that allows deep reductions in $\mathrm{CO}_{2}$ emissions. However, CCS in industrial applications has so far received little attention. Moreover, most studies on the potential application of CCS have focused on the power sector even though to achieve its full potential to reduce overall emissions, many other industry sectors must be considered [1-4].

Among the three steps of the $\mathrm{CCS}$ chain, $\mathrm{CO}_{2}$ capture is by far the most expensive one, accounting for $50-90 \%$ of the overall chain cost depending on the $\mathrm{CO}_{2}$ emission source. Chemical absorption with alkanolamines (or variants) is today the benchmark technology for $\mathrm{CO}_{2}$ capture 
from flue gas streams. This technology enables the sorbed $\mathrm{CO}_{2}$ in the form of stable carbamate and/or bicarbonate species to be further sequestrated in a separate vessel by raising the temperature and/or lowering the pressure, so that the regenerated solvent is recycled in the absorption unit. However, despite the maturity of this process, it still remains energy intensive and costly and it requires the installation of voluminous units [5].

Gas separation membranes are a potential alternative to the conventional $\mathrm{CO}_{2}$ capture methods. Many commercial membrane technologies are available and already been applied to natural gas sweetening, where the concentrations of $\mathrm{CO}_{2}$ and $\mathrm{H}_{2} \mathrm{~S}$ contained in high-pressure natural gas should be lowered to the levels of meeting the gas pipeline specifications. However, this does not necessarily ensure the feasibility of these membranes to flue gas treatment, because of several key differences between the two processes. Many different types of membranes have been considered for post-combustion $\mathrm{CO}_{2}$ capture, including glassy polymer membranes, facilitated transport membranes, mixed-matrix membranes and gas-liquid membrane contactors. These membranes have been extensively studied in lab or pilot scale, but no industrial application in flue gas treatment has been reported up to now [6].

Among the different available membrane technology methods, gas-liquid contact membranes seem to have the highest potential for large-scale applications, since they combine the advantages of gas separation polymeric membranes with that of absorption processes, creating a new way of contacting liquid and gases. In this respect, membrane gas absorption is a novel method with the advantages of higher efficiency, less required energy and lower costs in a more compact unit compared to the conventional absorption processes. Several extended reviews on gas-liquid contact membranes have been presented in the literature [7-9], where more details on the method and the potential applications can be found. $\mathrm{CO}_{2}$ capture from flue gases was among the first processes that attracted the scientific interest as a potential field of application and it is the currently most investigated target of membrane contactors. This application, initiated by Kvaerner Company in the late 1980s, clearly aims to use membrane contactors in a harsh environment which is very different from the clean, water-based applications developed up to now in the food and pharmaceutical sectors. The susceptibility of membrane material to wetting and membrane stability in chemically aggressive industrial environments are considered as the major hurdles for large-scale commercial applications [10].

In previous publications, our group studied both experimentally and theoretically $\mathrm{CO}_{2}$ capture from simulated flue gases using a membrane contactor, as well as the effect of membrane wetting in $\mathrm{CO}_{2}$ mass transfer resistance [11-
13]. The results indicated that $\mathrm{CO}_{2}$ capture with a membrane contacting process had very high potential for commercial application but the tests have to move from laboratory to a real industrial environment for a proof of concept validation in power generation as well as in other industry sectors. To the best of our knowledge, there are very few experiments conducted in real industrial environments, published in the open literature. Probably, the most prominent exception is the work conducted from the TNO group, who installed a membrane gas absorption pilot unit and studied $\mathrm{CO}_{2}$ capture from real flue gases, coming from a gas fired pilot plant [14].

The main goal of this study was the performance assessment of $\mathrm{CO}_{2}$ capture in a membrane gas absorption pilot unit installed in a Greek brick production industry ( $V$. Maliouris S.A.). In the brick production process, large quantities of $\mathrm{CO}_{2}$ are released to the atmosphere during bricks calcination. In this step, the bricks enter the process furnace where they are heated up to $\sim 950{ }^{\circ} \mathrm{C}$ using crude oil as a fuel. Crude oil combustion except of $\mathrm{CO}_{2}$ also results to the formation of $\mathrm{SO}_{2}, \mathrm{NO}_{x}$ and other trace elements which further increase the loading of gas pollutants in the atmosphere. The company, except of the environmental considerations, has also profits from $\mathrm{CO}_{2}$ emissions reduction, as it is placed in the Emissions Trading System (ETS) for $\mathrm{CO}_{2}$ emissions monitoring. The special feature of this process is that the system is far from steady state, mainly because of furnace doors opening when wagons with bricks enter and exit the furnace. This causes significant dilution of flue gases and variability with time. All the above render the effective application of a membrane gas absorption unit for $\mathrm{CO}_{2}$ capture, to be a very challenging task, which has not been studied extensively up to now.

\section{Experimental}

A sketch of the bricks calcination process of Maliouris S.A. is shown in Fig. 1. The flue gases move reversely to the bricks direction and exit from the flue of the kiln.

The main pollutants in the flue gases were determined before the installation of the membrane contactor pilot unit, using the following standard analysis methods:

- Humidity according to EN 14790:2005

- Particulate matter according to EN 13284:2001

- $\mathrm{HCl}$ according to EN 1911:2010

- $\quad$ VOC according to EN 13649:2002

- Smoke point according to ELOT 525.1

- The gases $\mathrm{O}_{2}, \mathrm{CO}, \mathrm{NO}, \mathrm{NO}_{2} \& \mathrm{SO}_{2}$ were determined with a portable gas analyzer with an electrochemical sensor and the $\mathrm{CO}_{2}$ with a portable gas analyzer with an NDIR sensor. 
Fig. 1 Sketch of the bricks calcination process

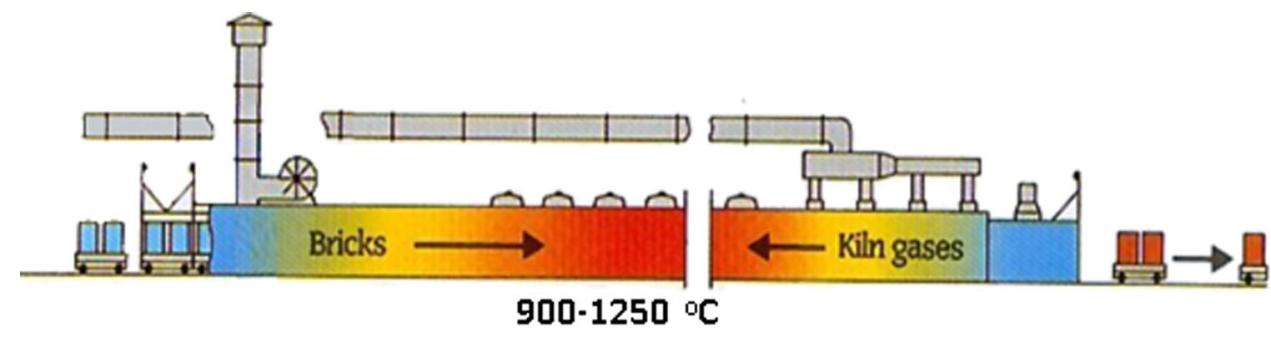

Various measurements were conducted at different time periods to account for the variations with time and to test the reproducibility of the methods.

In this study, a Liqui-Cel MiniModule $1 \times 5.5$ was used as a gas-liquid contactor. The main characteristics of the module are presented in Table 1. The gas flow is fed in the lumen side of the fibers and the liquid flow in the shell side of the module. The membrane acts as a barrier between gas and liquid phases and does not add selectivity for one gas species over the other. The gas fills the pores of the hydrophobic membrane but does not spread in the liquid as long as the pressure of the liquid phase is kept higher than that of the gas phase. Therefore, a gas-liquid interface is created at the pores mouth, where the absorption process takes place.

The membrane gas absorption pilot unit whose process flow diagram is shown in Fig. 2 was installed near the flue, where a slip stream of the flue gases was continuously sampled and fed in the lumen side of the hollow fiber membrane module. The slip stream was cooled down from $\sim 90$ to $\sim 30{ }^{\circ} \mathrm{C}$ and pretreated for particulate matter and water vapor removal before entering the membrane module. A 0.25 M aqueous (diethanolamine) DEA solution was chosen as a typical solvent for $\mathrm{CO}_{2}$ capture processes. The solvent was counter-currently fed in the shell side of the membrane module in a cross flow configuration, using an ISM446 BVP-Z Standard Gear Pump, chosen to provide a pulseless liquid flow. Figures 3 and 4 show two pictures of the equipment installed in Maliouris facilities for the pilot tests.

Table 1 Main characteristics of the Liqui-Cel MiniModule $1 \times 5.5$

\begin{tabular}{ll}
\hline Feature & Value \\
\hline Flow configuration & Parallel \\
Max. flow rate & $500 \mathrm{ml} / \mathrm{min}$ \\
Total length & $22 \mathrm{~cm}$ \\
Membrane material & Polypropylene \\
Membrane porosity & $40 \%$ \\
Outer (OD)/inner diameter (ID) & $300 \mu \mathrm{m} \mathrm{OD} / 220 \mu \mathrm{m} \mathrm{ID}$ \\
Number of fibers & 2300 \\
Effective membrane area & $0.18 \mathrm{~m}^{2}$ \\
\hline
\end{tabular}

\section{Results and discussion}

The mean concentrations of the main pollutants in the flue gases are shown in Table 2. The results indicated that the flue gas stream is loaded with a number of other pollutants which could have synergistic effects and affect the performance of the process compared to laboratory experiments. Based on the flue gas analysis, the slip stream was cooled down and filtered for humidity and PM removal to protect the membrane module located downstream.

Figure 5 illustrates the $\mathrm{CO}_{2}$ (left) and $\mathrm{NO}$ (right axis) concentration in the flue gas slip stream (inlet of the membrane module) with time. $\mathrm{CO}_{2}$ concentration varies between 0.5 and $3.75 \%$ in a 23 -min time period; the same behavior is observed for NO concentration varying between 5 and $60 \mathrm{ppm}$. This is due to a fluctuant dilution of the flue gases caused by the furnace doors opening when wagons with bricks enter and exit the furnace. Therefore, it is preferable to assess the module's performance by measuring the $\mathrm{CO}_{2}$ concentration in the inlet and outlet of the module continuously rather than working with mean concentrations.

The same figure depicts the temperature variation in the chimney and the membrane module inlet with time. It is evident that the same pattern with $\mathrm{CO}_{2} / \mathrm{NO}$ concentrations variations exists, which indicates that temperature and concentration curves are strongly correlated as they both are affected by the different steps of the furnace operation. When chimney's temperature falls below $90{ }^{\circ} \mathrm{C}$, it is anticipated that bricks' firing process has already been stalled and tunnel's cooling is in progress. Below this temperature there is also a decrease of the $\mathrm{CO}_{2} / \mathrm{NO}$ concentrations, while for higher temperatures these concentrations increase. A slight hysteresis of the temperature response may be attributed to gaseous accumulation within the tunnel, and most importantly due to the thermal inertia of the tunnel walls material to endure the high temperatures imposed by the process. The gaseous components are cooled before entering the membrane module not to exceed $40{ }^{\circ} \mathrm{C}$, so that the module's inlet temperature remains constant over time.

The $\% \mathrm{CO}_{2}$ removal was chosen as a typical performance indicator and the liquid to gas flow ratio as the main 


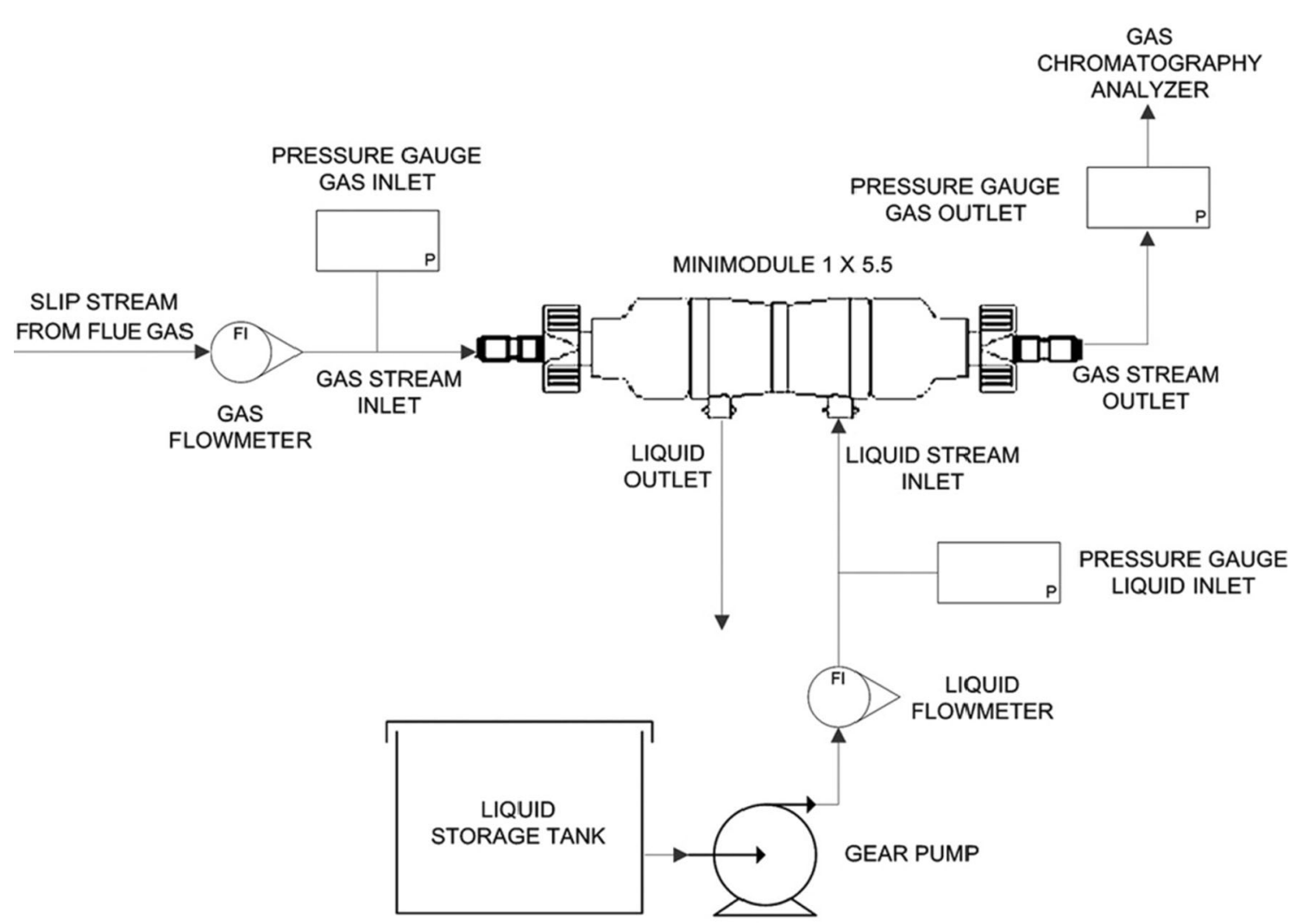

Fig. 2 Process flow diagram of the membrane contactor pilot unit

Fig. 3 Picture of the slip stream taken from the flue and the $\mathrm{CO}_{2}$ analyzer used for on-line measurements

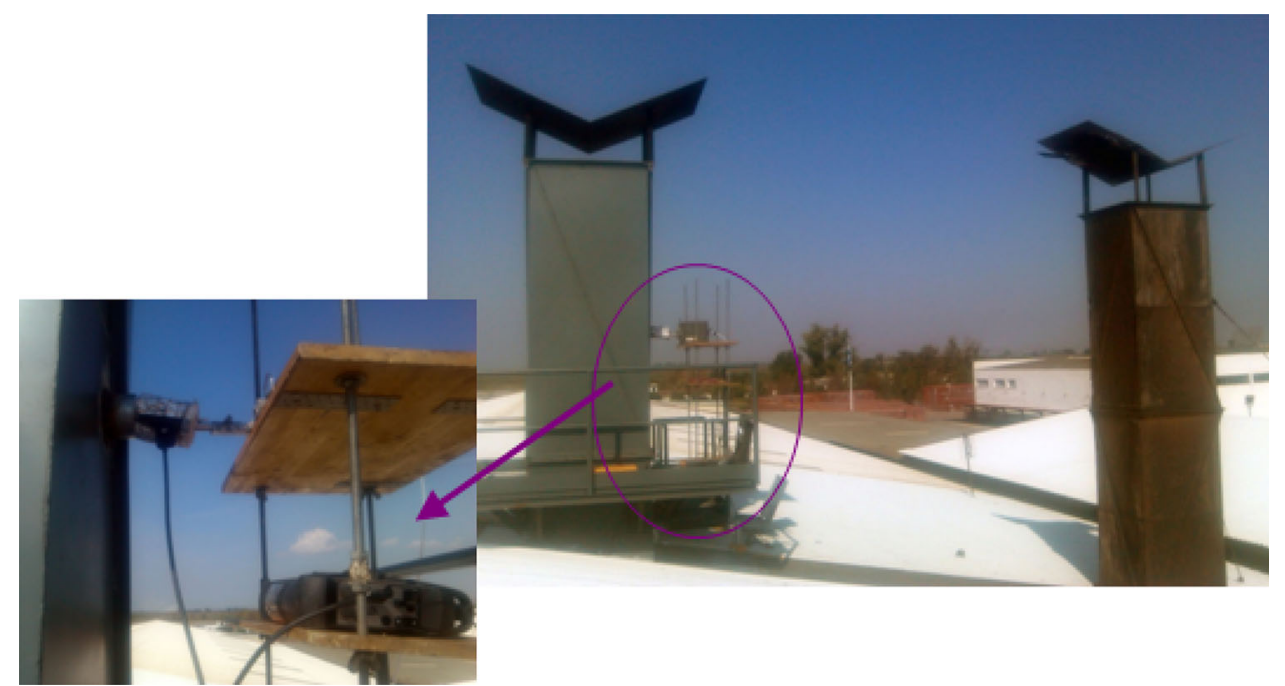

controlling variable of the process. In this study, four sets of experimental conditions were used to assess the performance of the membrane contactor process as indicated in Table 3, while the concentration of DEA remains constant at the mild level of $0.25 \mathrm{M}$. Specifically, four different liquid to gas flow rates were tested (starting from a low value of 0.09 and increasing up to 1.26) to study the effect of the main controlling variable to process performance. These four cases were developed on-site, by gradually increasing the liquid to gas flow rate until an almost complete $\mathrm{CO}_{2}$ capture was attained.

At this point, it must be noted that studying solvent regeneration after $\mathrm{CO}_{2}$ capture was out of the scopes of this study. DEA regeneration is an energy-intensive process which apparently affects process economics. However, it is a common problem met in any scrubbing process, 


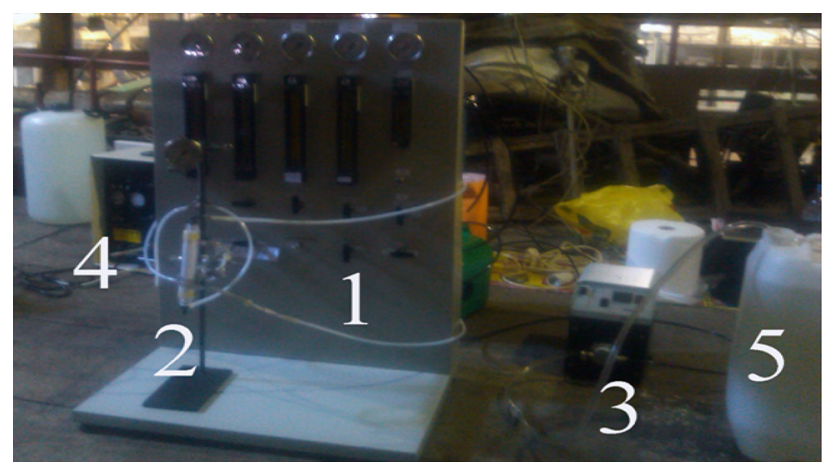

Fig. 4 Picture of the membrane contactor unit installed in Maliouris facilities for $\mathrm{CO}_{2}$ capture (1 Unit's control panel, 2 Membrane module, 3 Liquid feed pump, 4 Gas compressor installed in the gas outlet of the module, 5 DEA feed tank)

Table 2 Mean concentration of the main pollutants in the flue gases

\begin{tabular}{ll}
\hline Pollutant & Value \\
\hline $\mathrm{PM}\left(\mathrm{mg} / \mathrm{Nm}_{\text {dry }}^{3}\right)$ & 9.53 \\
$\mathrm{HCl}\left(\mathrm{mg} / \mathrm{Nm}_{\text {dry }}^{3}\right)$ & 0.52 \\
VOCs $\left(\mathrm{mg} / \mathrm{Nm}_{\text {dry }}^{3}\right)$ & 1.07 \\
Smoke point (Bacharach scale) & $2-3$ \\
Humidity (\% v/v wet) & 8.7 \\
$\mathrm{O}_{2}(\%$ v/v dry) & 18.1 \\
$\mathrm{CO}_{2}(\%$ v/v dry $)$ & 2.2 \\
$\mathrm{CO}_{(\mathrm{ppm}}$ dry $)$ & 110 \\
$\mathrm{NO}_{\left(\mathrm{ppm}_{\mathrm{v}} \text { dry }\right)}$ & 56 \\
$\mathrm{NO}_{2}\left(\mathrm{ppm}_{\mathrm{v}}\right.$ dry) & 2 \\
$\mathrm{SO}_{2}\left(\mathrm{ppm}_{\mathrm{v}}\right.$ dry $)$ & 18 \\
\hline
\end{tabular}

regardless of how $\mathrm{CO}_{2}$ capture was realized, which must be separately studied.

Figure 6 shows the test results for Case A. Specifically, the molar fraction of $\mathrm{CO}_{2}$ in the inlet and outlet stream of the membrane module, and the respective $\mathrm{CO}_{2}$ recovery attained, with time, are presented. In Case A where a low liquid to gas flow rate was chosen, the $\mathrm{CO}_{2}$ molar fraction at the outlet, as well as the $\mathrm{CO}_{2}$ recovery, varies according to the variation of $\mathrm{CO}_{2}$ at the inlet. A maximum of $~ 90 \%$ recovery can be attained when the inlet $\mathrm{CO}_{2}$ is low, which drops to $\sim 60 \%$ when the inlet $\mathrm{CO}_{2}$ is high. This indicates that the liquid flow rate is inadequate to handle the feed gas stream and higher liquid to gas flow rate must be used.

Figure 7 shows the test results for Case B. When a higher liquid to gas flow rate was used the molar fraction of $\mathrm{CO}_{2}$ in the outlet as well as the $\mathrm{CO}_{2}$ recovery, after an initial transient period tend to reach a plateau despite the fluctuation of $\mathrm{CO}_{2}$ concentration in the inlet. In this case, a $\sim 90 \% \mathrm{CO}_{2}$ recovery can be attained.

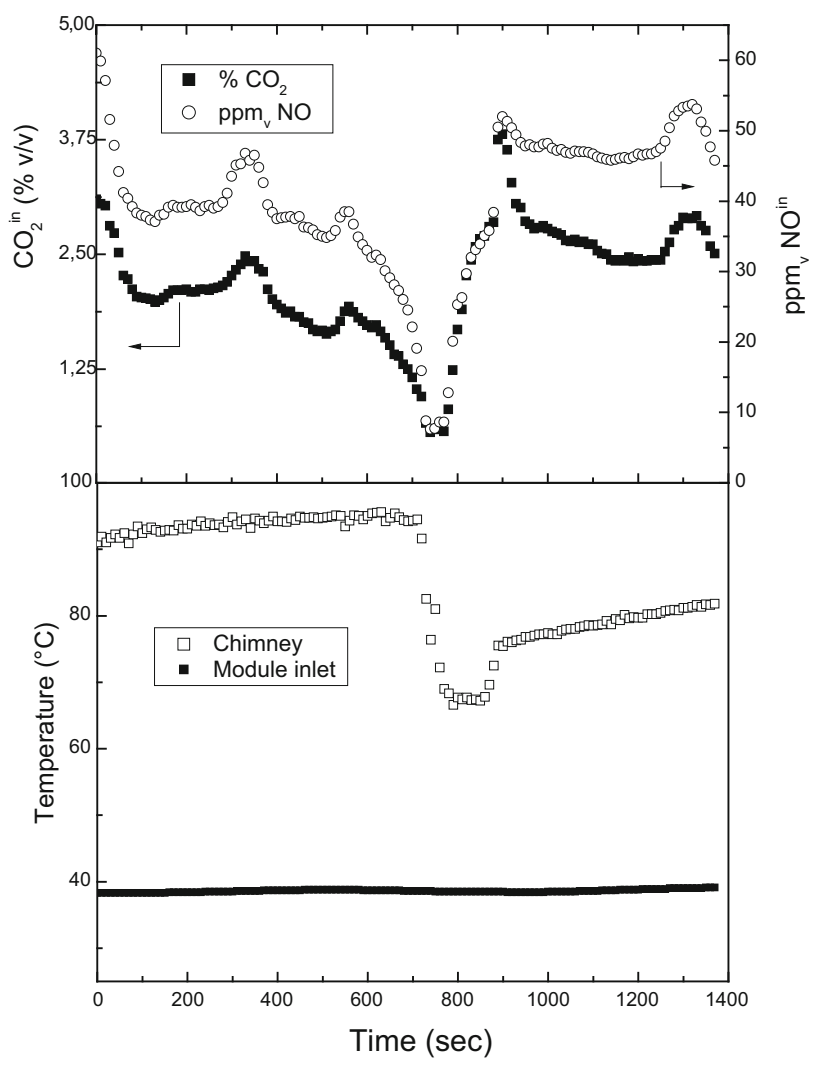

Fig. $5 \mathrm{CO}_{2}$ and $\mathrm{NO}$ concentration in the flue gas slip stream, and correlation with chimney and module inlet temperature variation with time

Figure 8 shows the test results for Case $\mathrm{C}$ where a higher liquid to gas flow rate was used. In this case, the system has no observable variation regarding the outlet $\mathrm{CO}_{2}$ concentration and $\mathrm{CO}_{2}$ recovery despite the fluctuation of the inlet $\mathrm{CO}_{2}$ concentration. In this case, a 95\% $\mathrm{CO}_{2}$ recovery can be attained.

Figure 9 shows the test results for Case D where the highest liquid to gas flow rate ratio of the set examined was used, exceeding unity. In this case, the system has the same behavior as in Case $\mathrm{C}$ but a $\sim 98 \% \mathrm{CO}_{2}$ recovery can be achieved.

An overall assessment of the test results confirms that the liquid to gas flow rate is the main controlling variable of the process. The membrane-based gas absorption process premises $\mathrm{CO}_{2}$ transport from gas to the liquid phase. This mass transport phenomenon can be described with a resistance in series model. Specifically, three different resistances can be identified; the gas phase resistance, the membrane resistance and the liquid phase resistance, with $\mathrm{CO}_{2}$ concentration gradient to be the driving force in any case. As the liquid to gas flow rate increases all the resistances decrease and the $\mathrm{CO}_{2}$ recovery increases. This is caused both by the improved hydrodynamic conditions as 
Table 3 Main process variables for the different cases tested for $\mathrm{CO}_{2}$ capture

\begin{tabular}{lllllll}
\hline Case & $T\left({ }^{\circ} \mathrm{C}\right)$ & $P(\mathrm{~atm})$ & $Q_{1}(\mathrm{cc} / \mathrm{min})$ & $Q_{g}(\mathrm{cc} / \mathrm{min})$ & $Q_{l} / Q_{g}$ & DEA concentration (M) \\
\hline A & 31 & 1 & 50.8 & 550.9 & 0.09 & 0.25 \\
B & 30 & 1 & 314.7 & 527.2 & 0.60 & 0.25 \\
C & 31 & 1 & 490.6 & 521.3 & 0.94 & 0.25 \\
D & 32 & 1 & 490.6 & 389.0 & 1.26 & 0.25 \\
\hline
\end{tabular}

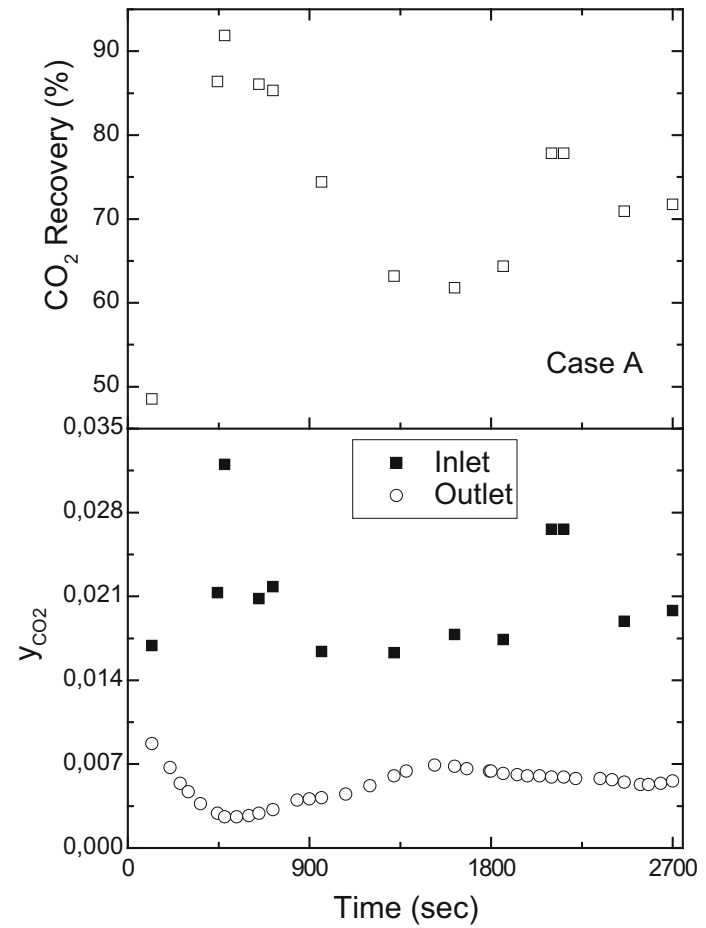

Fig. $6 \mathrm{CO}_{2}$ recovery and molar fraction in the inlet/outlet of the module for Case A

well as by the increased driving force, due to the lower $\mathrm{CO}_{2}$ concentration in the liquid phase [11, 15]. Therefore, we can precisely control the overall process performance, according to the specific process needs, by controlling the liquid to gas flow rate. It is evident that high liquid to gas flow rates could lead to an almost complete $\mathrm{CO}_{2}$ capture, which would not be affected by $\mathrm{CO}_{2}$ concentration variation in the flue gases. However, this would lead to high solvent consumption, which would negatively affect the process economics, rendering it unpractical for industrial application.

At this point, it must be noted that a detailed technoeconomic analysis and a feasibility study of the proposed technology are out of the scopes of this study. Nevertheless, it can be noted that a comparison of the proposed technology with the conventional gas absorption towers is in favor of membrane technology when substantial benefits are expected by the much smaller volume and high flexibility of membrane contactors relative to packed columns,

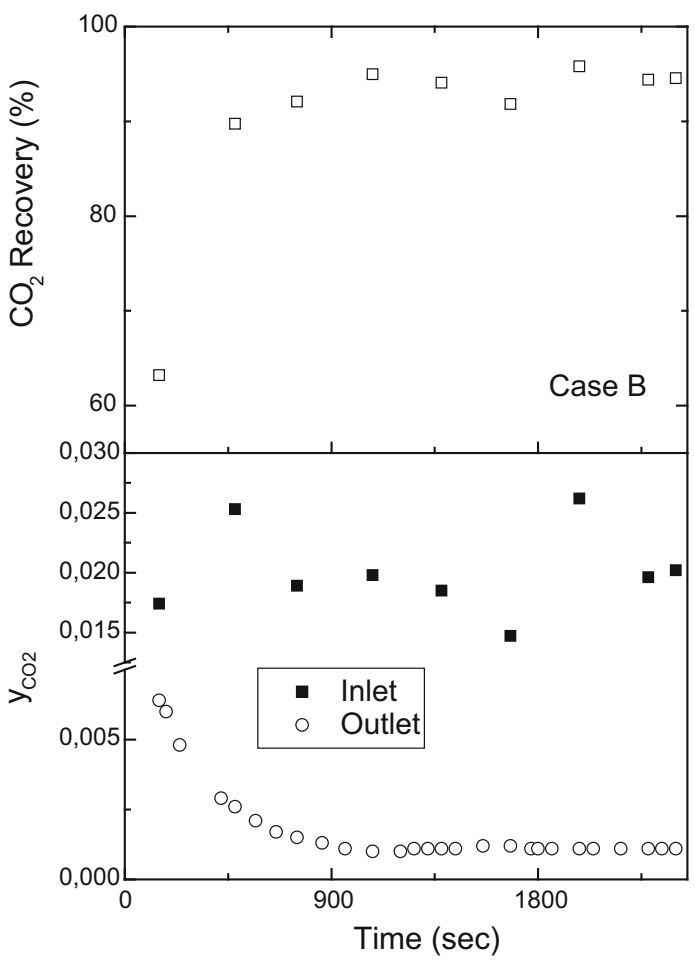

Fig. $7 \mathrm{CO}_{2}$ recovery and molar fraction in the inlet/outlet of the module for Case B

since the use of a membrane absorber can lead to a tenfold reduction in equipment size [11, 14]. However, it is often pointed out in the literature that the price of the membranes must be reduced and their reliability must be increased to displace the well-established technologies [16, 17].

\section{Conclusions}

A membrane contactor pilot unit was installed and tested for $\mathrm{CO}_{2}$ capture from the flue gases of a Greek brick production industry. The special feature of this process compared to the common combustion ones is that the system is far from steady state and the $\mathrm{CO}_{2}$ concentration in the flue gases strongly varies with time. The $\mathrm{CO}_{2}$ recovery was chosen as a typical performance indicator and the liquid (0.25 $\mathrm{M}$ aqueous DEA solution) to gas flow ratio as the main controlling variable of the process. The experimental results indicated that a steady $\mathrm{CO}_{2}$ capture of $90-95 \%$ can 


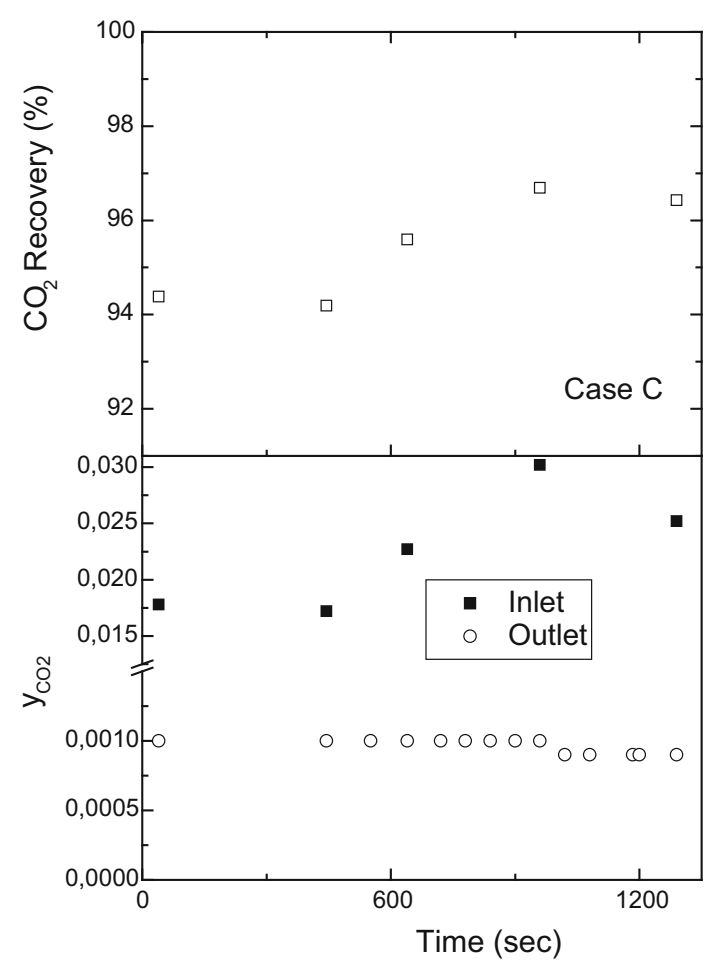

Fig. $8 \mathrm{CO}_{2}$ recovery and molar fraction in the inlet/outlet of the module for Case $\mathrm{C}$

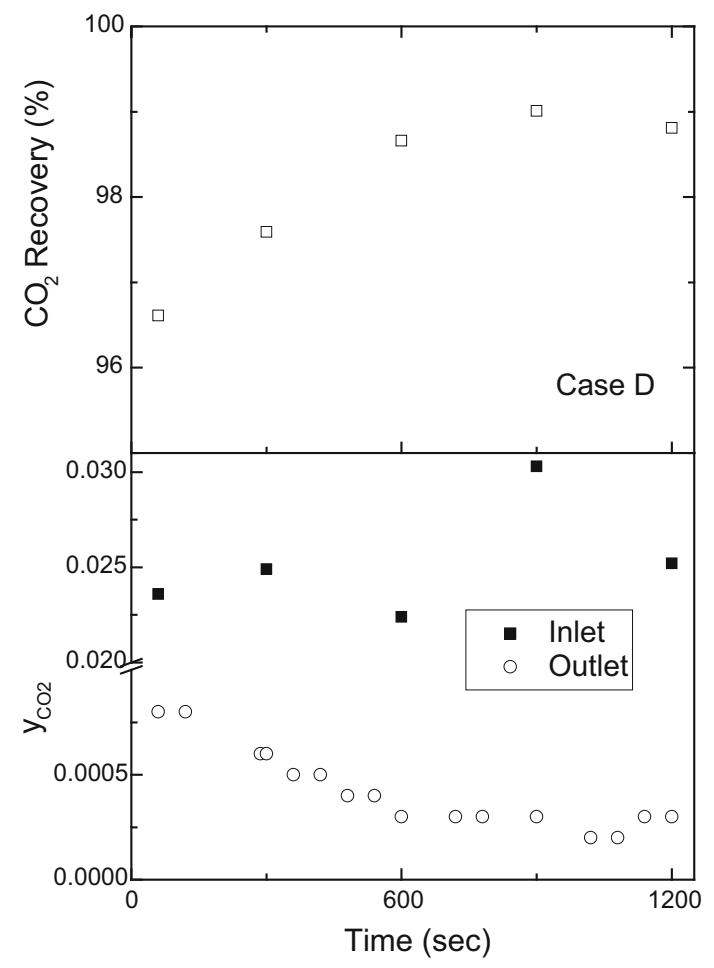

Fig. $9 \mathrm{CO}_{2}$ recovery and molar fraction in the inlet/outlet of the module for Case D be achieved using mild concentration of the amine solution regardless of the $\mathrm{CO}_{2}$ concentration variation in the flue gases, using a liquid to gas flow rate of 0.6-0.95. Lower liquid to gas flow rate ratios have a poor performance presenting high variation (depending on the fluctuation of $\mathrm{CO}_{2}$ concentration in the flue gases), but still higher than $60 \%$; higher liquid to gas flow rate ratios require high solvent consumption with marginal increase in $\mathrm{CO}_{2}$ capture. An overall assessment of the process demonstrates the high potential and flexibility of the proposed technology to post-combustion $\mathrm{CO}_{2}$ capture in many industrial sectors.

Acknowledgments The authors would like to thank the General Secretariat for Research and Technology for financial support of this work through: $\mathrm{CO}_{2} \mathrm{MembraneCapture} \mathrm{Project} \mathrm{of} \mathrm{NSRF} \mathrm{2007-2013}$ (Contract No. 09SYN-32-719).

Open Access This article is distributed under the terms of the Creative Commons Attribution 4.0 International License (http://crea tivecommons.org/licenses/by/4.0/), which permits unrestricted use, distribution, and reproduction in any medium, provided you give appropriate credit to the original author(s) and the source, provide a link to the Creative Commons license, and indicate if changes were made.

\section{References}

1. Zhang, Z.E., Yan, Y.F., Zhang, I., Ju, S.X.: Hollow fiber membrane contactor absorption of $\mathrm{CO}_{2}$ from the flue gas: review and perspective. Glob. Nest J. 16, 354-373 (2014)

2. van der Hoeven, M., Yumkella, K.K.: Technology roadmap, carbon capture and storage in industrial applications. IEA UNIDO (2011)

3. Karki, J., Tsupari, E., Arasto, A.: CCS feasibility improvement in industrial and municipal applications by heat utilization. Energy Procedia. 37, 2611-2621 (2013)

4. Sreenivasulu, B., Gayatri, D.V., Sreedhar, I., Raghavan, K.V.: A journey into the process and engineering aspects of carbon capture technologies. Renew. Sustain. Energy Rev. 41, 1324-1350 (2015)

5. Pera-Titus, M.: Porous inorganic membranes for $\mathrm{CO}_{2}$ capture: present and prospects. Chem. Rev. 114, 1413-1492 (2014)

6. Khalilpour, R., Mumford, K., Zhai, H., Abbas, A., Stevens, G., Rubin, E.S.: Membrane-based carbon capture from flue gas: a review. J. Clean. Prod. 103, 286-300 (2015)

7. Gabelman, A., Hwang, S.-T.: Hollow fiber membrane contactors. J. Membr. Sci. 159, 61-106 (1999)

8. Li, J.-L., Chen, B.H.: Review of $\mathrm{CO}_{2}$ absorption using chemical solvents in hollow fiber membrane contactors. Sep. Purif. Technol. 41, 109-122 (2005)

9. Mansourizadeh, A., Ismail, A.F.: Hollow fiber gas-liquid membrane contactors for acid gas capture: a review. J. Hazard. Mater. 171, 38-53 (2009)

10. Chabanon, E., Belaissaoui, B., Favre, E.: Gas-liquid separation processes based on physical solvents: opportunities for membranes. J. Membr. Sci. 459, 52-61 (2014)

11. Mavroudi, M., Kaldis, S.P., Sakellaropoulos, G.P.: Reduction of $\mathrm{CO}_{2}$ emissions by a membrane contacting process. Fuel 82, 2153-2159 (2003) 
12. Mavroudi, M., Kaldis, S.P., Sakellaropoulos, G.P.: A study of mass transfer resistance in membrane gas-liquid contacting processes. J. Membr. Sci. 272, 103-115 (2006)

13. Pantoleontos, G., Kaldis, S.P., Koutsonikolas, D., Skodras, G., Sakellaropoulos, G.P.: Analytical and numerical solutions of the mass continuity equation in the lumen side of a hollow-fiber membrane contactor with linear or nonlinear boundary conditions. Chem. Eng. Commun. 197, 709-732 (2010)

14. Klaassen, R., Feron, P.H.M., Jansen, A.E.: Membrane contactors in industrial applications. Chem. Eng. Res. Des. 83, 234-246 (2005)
15. Hoff, K.A., Svendsen, H.F.: Membrane contactors for $\mathrm{CO}_{2}$ absorption-application, modeling and mass transfer effects. Chem. Eng. Sci. 116, 331-341 (2014)

16. Yan, S., Fang, M., Wang, Z., Xue, J., Luo, Z.: Economic analysis of $\mathrm{CO}_{2}$ separation from coal-fired flue gas by chemical absorption and membrane absorption technologies in China. Energy Procedia. 4, 1878-1885 (2011)

17. Kimball, E., Al-Azki, A., Gomez, A., Goetheer, E., Booth, N., Adams, D., Ferre, D.: Hollow fiber membrane contactors for $\mathrm{CO}_{2}$ capture: modeling and up-scaling to $\mathrm{CO}_{2}$ capture for an $800 \mathrm{MWe}$ coal power station. Oil Gas Sci. Technol. 69, 1047-1058 (2014) 